\title{
Isolation and Characterization of Lactic Acid Bacteria from Kimchi, Korean Traditional Fermented Food to Apply into Fermented Dairy Products
}

\author{
Young-Hee Cho', Sung-Moon Hong, and Cheol-Hyun Kim* \\ Department of Animal Resource \& Science, Dankook University, Cheonan 330-714, Korea \\ ${ }^{1}$ Danone Korea R\&I Center, Seoul 136-701, Korea
}

\begin{abstract}
This study aimed to isolate lactic acid bacteria (LAB) from Kimchi and to identify suitable probiotic strain for application in fermented dairy product as a commercial starter culture. A total of 106 (LAB) strains were isolated from Kimchi collected from different regions in Korea and their phenotypic characteristics were assayed. Four isolates from MRS agar plates were selected and designated as DKL109, DKL119, DKL121 and DKL128. They were identified first by API 50 CHL kit and then 16S rRNA gene sequencing. DKL121 and DKL128 were identified as Lactobacillus paracasei and Lactobacillus casei, respectively. Other two isolates (DKL109 and DKL119) were identified as Lactobacillus plantarum. To estimate their applicability in dairy products, the characteristics including acid and bile tolerance, cold shock induced cryotolerance and enzymatic activities were determined. There was wide variation in ability of strains to acid tolerance, but no significant differences in bile tolerance, cold shock induced cryotolerance within selected strains. DKL119 and DKL121 showed the highest resistance to acid and bile and the highest $\beta$-galactosidase activity, respectively. When these two strains were used for yogurt preparation as a single starter culture, their viable cell counts reached to $1.0 \times 10^{9} \mathrm{CFU} / \mathrm{mL}$. Lactobacillus plantarum DKL119 showed faster acid development than commercial starter culture. Also storage trials at $10^{\circ} \mathrm{C}$ showed that the viability of these strains was retained over $15 \mathrm{~d}$. With these results, it was indicated that probiotics isolated from Kimchi can be used in yogurt manufacturing as a starter culture.
\end{abstract}

Key words: lactic acid bacteria, acid and bile tolerance, cryotolerance, $\beta$-galactosidase activity, fermented dairy product

\section{Introduction}

Functional foods containing probiotic bacteria, mainly lactic acid bacteria $(\mathrm{LAB})$ have been received increasing interest in the marketplace because of the health benefits ascribed to probiotics (Gerez et al., 2012). Probiotic microorganisms are mostly of human or animal origin: however, some studies show that strains recognized as probiotics are also found in non-dairy fermented foods (Bamidele et al., 2011; Rivera-Espinoza and GalladoNavarro, 2010). The isolation of lactic acid bacteria from fresh vegetables also appears to be interesting since they can present affordable source of the organisms.

Over centuries, fermentation has been used to preserve, improve the quality or modify the flavor of cereals, fruits, vegetables, legumes and meats. As fermentation process

\footnotetext{
*Corresponding author: Cheol-Hyun Kim, Department of Animal Resource \& Science, Dankook University, Cheonan 330-714, Korea. Tel: 82-41-550-3656, Fax: 82-41-622-3656, E-mail: hichkim@dankook.ac.kr
}

involves mixed cultures such as yeast, LAB and fungi, traditional fermented foods are a plentiful source of microorganism and some of them show probiotic characteristics (Rivera-Espinoza and Gallado-Navarro, 2010). Numerous studies have been undertaken to obtain scientific evidences for the beneficial effects of fermented foods containing probiotic bacteria (Succi et al., 2005).

Kimchi, being a lactic acid-fermented vegetable product consumed raw, is considered to be a good source of potentially beneficial and useful LAB. A wide range of such desired roles have been suggested for diverse strains of LAB, including immune stimulation, pathogen exclusion, production of bioactive substances, and general intestinal health (Lee et al., 2011). The microorganisms involved in Kimchi fermentation include about 200 species of bacteria (Liang et al., 2011; Yang and Chang, 2009). Since health benefits imparted by probiotic bacteria are strain specific, several researches (Kim et al., 2003; Lee et al., 2007; Lee et al., 2011; Lee et al., 2012; Liang et al., 2011; Shin et al., 2008; Yang and Chang, 2009) on isolation and characterization of LAB from 
Kimchi have been conducted. However, there is lack of research focused on commercialization and application to dairy products.

When selecting strains of probiotic microorganism for use in foods, a number of criteria must be taken into account. The most important requirements are viability and survival of probiotic bacteria in sufficient numbers in the product (Gerez et al., 2012; Heller, 2001; Succi et al., 2005). A number of factors have been claimed to affect the viability of probiotic bacteria in dairy foods, including low $\mathrm{pH}$, bile acid and refrigerated storage. Moreover, the resistance to human gastric transit constitutes an important selection criterion for probiotic bacteria (Gerez et al., 2012; Succi et al., 2005). Technological requirements including good sensory properties, viability during starter preparation and survival in the manufactured products are also important. Freeze-dried or lyophilised yogurt cultures dried in the frozen state, and deep frozen culture types are currently popular preservation methods for commercial starter cultures. This method of starter preservation enjoys widespread popularity because it provides a high number of viable organisms and the maximum percentage survival during storage, compared with vacuum or spraydried starter cultures. Response to freezing stress is often passive and leads to a decrease in viability and metabolic activity that is associated with Cryoinjury (Rivals et al., 2007). Therefore understanding of cold-shock-induced cryotolerance may contribute to development of environmental conditions that allow improved viability/activity of frozen or freeze-dried commercial LAB starter cultures (Kim and Dunn, 1997).

The aims of this research are to isolate and identify strains of potentially probiotic bacteria from Kimchi, traditional Korean fermented foods and to assess $\beta$-galacosidase and proteolytic activity, and resistant under harsh conditions such as bile salt, low $\mathrm{pH}$ and cold-shock for commercial use as probiotics and starter culture in dairy products.

\section{Materials and Methods}

\section{Materials and commercial strains}

Sodium azide and $\mathrm{MgSO}_{4}$ were obtained from Junsei (Japan). Oxgall, MRS agar and MRS broth were obtained from Difco (USA). $\mathrm{HCl}$ and $\mathrm{Na}_{2} \mathrm{CO}_{3}$ were obtained from Daejung (Korea). Agar powder, $\beta$-mercaptoethanol, sodium dodecyl sulfate (SDS), $\sigma$-nitrophenyl- $\beta$-D-galactopyranoside (ONPG), and sodium acetate trihydrate were obtained from Sigma (USA). Gram stain kit was obtained from YD Diagnostics (Korea). Lactic acid was obtained from Konto
(Japan). BCP agar was obtained from Aiken (Japan). Skim milk was obtained from Seoul dairy co-op. (Korea). Chloroform was obtained from J.T. Baker (USA). Four commercial strains: L. casei (LC-10, Culture system, USA), L. plantarum (LP-5, Culture system, USA), $S$. thermophilus (ST-body1, Culture system, USA) and $S$. thermophilus (Yomix-321, Danisco, Denmark) were used in this study depending on the purpose of use.

\section{Sample collection and isolation of lactic acid bacteria}

Lactic acid bacterial strains were isolated from homemade and commercial Kimchi which were collected from different regions in Korea. Each sample was mixed with PBS with the ratio of $1: 1$ and homogenized using a stomacher (Interscience, France). One milliliter of diluted samples were serially diluted with $0.85 \%$ saline, then 100 $\mu \mathrm{L}$ of each dilution was spread onto MRS agar containing $0.02 \%$ sodium azide and the plates were incubated at $37^{\circ} \mathrm{C}$ for $48 \mathrm{~h}$. Representative colonies were picked from plates and well-isolated colonies were inoculated into fresh MRS broth for stock preparation. For long term storage, stock cultures were maintained at $-20^{\circ} \mathrm{C}$ in MRS broth containing $15 \%$ glycerol.

\section{Screening and identification of Lactic acid bacteria}

Screening of selected isolates was conducted by observation of colony shape on plates, gram staining, and observation of cell morphology using microscope. Selected isolates were identified first by using an API kit (API 50 CHL, BioMerieux, France) and then by 16S rRNA gene sequencing. 16S ribosomal RNA coding gene was amplified by direct PCR using universal primers: forward; 5'GAGTTGGATCCTGGCTCAG-3' and reverse; 5'-AAGGAGGGGATCCAGCC-3'. The reaction mixture consisted of $300 \mathrm{mM}$ Tris- $\mathrm{HCl}(\mathrm{pH} 8.8), 100 \mathrm{mM}\left(\mathrm{NH}_{4}\right)_{2} \mathrm{SO}_{4}, 100$ $\mathrm{mM} \mathrm{KCl}, 20 \mathrm{mM} \mathrm{MgSO}_{4}, 20 \mathrm{pM}$ of each primer, $20 \mathrm{mM}$ of each dNTP, 2 Unit of Taq polymerase (Genenmed, USA), and a 20 ng template. Amplification was conducted for 30 cycles of the following conditions: $1 \mathrm{~min}$ at $95^{\circ} \mathrm{C}, 1 \mathrm{~min}$ of annealing at $55^{\circ} \mathrm{C}$, and $2 \mathrm{~min}$ of extension at $72^{\circ} \mathrm{C}$ using a PCR machine (T Gradient model, Biometera, Germany). The PCR products were directly sequenced with an ABI Prism 3700 genetic analyzer at the Macrogen, Inc. (Korea). The $16 \mathrm{~S}$ rDNA sequences were analyzed using the GenBank database, and identification was performed on the basis of 16S rDNA sequence homology.

\section{Bile salt and acid tolerance}

Selected strains were tested for their resistance to dif- 
ferent stress factors and compared with the commercial strain, LP-5 and LC-10. To assay acid tolerance, cultures were inoculated in the MRS broth adjusted to $\mathrm{pH} 2.0$ with $1.0 \mathrm{~N} \mathrm{HCl}$, then incubated at $37^{\circ} \mathrm{C}$ for 1 or $2 \mathrm{~h}$. Bacterial growth was observed with enumerated viable colony at the MRS agar plates incubated at $37^{\circ} \mathrm{C}$ for $48 \mathrm{~h}$. For bile tolerance, cultures were inoculated in the MRS broth supplemented with $1.0 \%$ oxgall, then incubated at $37^{\circ} \mathrm{C}$ for 2 h. The survival was ascertained as described above.

\section{Assay for $\beta$-galactosidase activity}

$\beta$-galactosidase activity was measured according to the method of Jalili et al. (2009). One mL of culture was added to $50 \mathrm{~mL}$ of $0.1 \mathrm{M}$ phosphate buffer containing $0.001 \mathrm{M}$ $\mathrm{MgSO}_{4}$ and $0.05 \mathrm{M} \beta$-mercaptoethanol. Then, two drops of chloroform and one drop of $1 \%(\mathrm{w} / \mathrm{v})$ sodium dodecyl sulfate were added to $1 \mathrm{~mL}$ of the diluted sample. After vortexing for $10 \mathrm{~s}$, mixture was placed in a water bath at $28^{\circ} \mathrm{C}$ for $5 \mathrm{~min}$. And then, $0.2 \mathrm{~mL}$ of $4 \mathrm{mg} / \mathrm{mL} o$-nitrophenyl- $\beta$-D-galactopyranoside (ONPG) was added to the mixture and vortexed for $10 \mathrm{~s}$. The reaction catalyzed by $\beta$-galactosidase was quenched for $10 \mathrm{~min}$ via addition of $0.5 \mathrm{~mL}$ of $1 \mathrm{M} \mathrm{Na}_{2} \mathrm{CO}_{3}$. Following centrifugation at 15,000 $g$ for $15 \mathrm{~min}$, the optical density was measured at $420 \mathrm{~nm}$ using an ELISA reader (TECAN, Salzburg, Austria). The following formula was used to estimate the enzyme activity:

Activity of $\beta$-galactosidase (unit/mL) $=\mathrm{A} 420 / \mathrm{tv} \times 100$

where $t, v$ and A420 denote time of reaction ( $\mathrm{min}$ ), volume of sample $(\mathrm{mL})$ and absorbance $(420 \mathrm{~nm})$, respectively. All chemicals used were from Merck (Germany).

\section{Determination of lactose content}

Lactose content was determined according to the method of Kim and Kwak (1993) with modification. Five mL of yogurt fermented by selected strains were mixed with 10 $\mathrm{mL}$ of $1.6 \% \mathrm{HPO}_{3}$ and stood at room temperature for $2 \mathrm{~h}$. This mixture was centrifuged at 7,000 $\mathrm{g}$ for $10 \mathrm{~min}$, and then filtered with membrane filter (pore size $0.45 \mu \mathrm{m}$ ). The analysis of lactose content by high performance liquid chromatography (HPLC) was performed using a Waters 600 controller with a Waters W410 reflective index (RI) detector (Waters, USA). The chromatographic analysis was conducted using carbohydrate column $(3.9 \mathrm{~mm} \times 300 \mathrm{~mm}$, particle size $10 \mu \mathrm{m}$, Waters, USA). The mobile phase used was acetonitrile:deionized water $(8: 2 ; \mathrm{v} / \mathrm{v})$. The chromatographic separation of samples $(10 \mu \mathrm{L})$ was performed at a constant flow rate of $1 \mathrm{~mL} / \mathrm{min}$. The concentration was calculated by using the peak area obtained with standard sugars (lactose, galactose, and glucose) obtained from Sigma (USA).

\section{Assay for proteolytic activity}

Proteolytic activity was assessed by an agar diffusion method according to the method of Riffel and Brandelli (2006) with slight modification. Milk agar plates containing $1.6 \%$ skim milk and $1.5 \%$ agar were prepared. A 0.3 $\mathrm{mL}$ of each strain at a final concentration of about $10^{8}$ $\mathrm{CFU} / \mathrm{mL}$ was inoculated onto plates and incubated $37^{\circ} \mathrm{C}$ for $48 \mathrm{~h}$. Absence of inhibitory zone was observed.

\section{Freeze-thaw challenge and survival measurement}

Freeze-thaw challenge was performed by applying 3 freeze-thaw cycles combining a freezing $\left(-40^{\circ} \mathrm{C}, 24 \mathrm{~h}\right)$ and a thawing $\left(37^{\circ} \mathrm{C}, 3 \mathrm{~min}\right)$. Strains were incubated at $37^{\circ} \mathrm{C}$ for $24 \mathrm{~h}$, harvested by centrifugation, washed and re-suspended in sterile water and frozen in $1 \mathrm{~mL}$ aliquots. Every $24 \mathrm{~h}$ the frozen cells were thawed and refrozen. At each freeze-thaw cycle, the population of survivors was determined.

\section{Yogurt preparation}

The yogurt was made from a $92 \%$ whole milk in which the solids content was increased by addition of 3\% oligosaccharide and 5\% skim milk. The milk was then homogenized, pasteurized at $95^{\circ} \mathrm{C}$ for $15 \mathrm{~min}$, cooled to about $40^{\circ} \mathrm{C}$, and inoculated at a rate of $20 \mathrm{~mL} / \mathrm{L}\left(10^{9} \mathrm{CFU} /\right.$ $\mathrm{mL}$ ) with a probiotic isolate previously triplicates subcultured in MRS broth. The milk was incubated at $40^{\circ} \mathrm{C}$ until the desired titratable acidity of 0.7 had developed. Yogurt containing commercial strain also prepared as above. Every $2 \mathrm{~h}$, samples were taken to measure the titratable acidity and viable cell counts.

\section{Storage stability}

Samples of yogurt containing one of the selected isolates or commercial strains were stored at 10 and $15^{\circ} \mathrm{C}$ to monitor the effect of storage on the viability of the probiotic species and the changes in titratable acidity. The titratable acidity and counts of the probiotic starter cultures were determined after $0,5,10$ and $15 \mathrm{~d}$ of storage.

\section{Results and discussion}

\section{Identification of isolates}

A total of 106 strains were isolated from Kimchi samples. The colony characteristics of isolates obtained were observed along with their colony shape, Gram reaction 
and microscopic examination. Gram positive, non-motile and rod shaped bacteria showing phenotypic characters similar to Lactobacillus species on MRS agar media and being able to growth at $\mathrm{pH} 4.4$ were selected for further studies. Four isolates of single colony were selected and designated as DKL109, DKL119, DKL121 and DKL128.

Identification was first tried by using an API $50 \mathrm{CHL}$ kit. Two isolates (DKL109 and DKL119) were identified as L. plantarum and others (DKL121 and DKL128) were L. curvetus. 16S rRNA gene sequencing was done to confirm the identification results by API kit. DKL109 and DKL119 were confirmed as L. plantarum based on $16 \mathrm{~S}$ rRNA gene sequencing ( $99 \%$ similarity to GeneBank sequences). However, DKL121 and DKL128 were identified as $L$. paracasei $(100 \%$ similarity to GeneBank sequences) and $L$. casei, respectively.

L. plantarum is one of the predominant species in Kimchi with Leuconostoc mesenteroides (Lim and Im, 2009). Many researches (Lee et al., 2007; Lee et al., 2011; Lim and Im, 2009) also isolated L. plantarum and studied their functional characteristics. However, there were few studies on the isolation of $L$. paracasei and $L$. casei from Kimchi and their characteristics.

\section{Acid and bile tolerance}

Microorganisms ingested with food begin their journey to the lower intestinal tract via the mouth and are exposed during their transit through the gastrointestinal tract to successive stress factors that influence their survival. Cellular stress begins in the stomach, which has $\mathrm{pH}$ as low as 1.5. Bile secreted in the small intestine reduces the survival of bacteria by destroying their cell membranes (Succi et al., 2005). This bile salt presence creates more stressful condition for probiotics. Therefore, resistance to low $\mathrm{pH}$ and bile is the important characteristics for probiotics.

Table 1 showed the ability of isolated strains and commercial strains to survive at acid environment at $\mathrm{pH}$ 2.0. Even though there was wide variation in ability of strains to acid tolerance, all 4 isolated strains showed better acid tolerance than commercial strains none of which survived within $1 \mathrm{~h}$. DKL119 was a sole strain which viable cell count remained to $2 \mathrm{~h}$. The viable cell count of DKL109 reduced after $1 \mathrm{~h}$ but remained after $2 \mathrm{~h}$. DKL128 survived at $\mathrm{pH} 2$ for $1 \mathrm{~h}$ which is in agreement with the study by Mishra and Prasad (2005).

The mean intestinal bile concentration is $0.3 \%$ and the staying time of food in small intestine is suggested to be $4 \mathrm{~h}$ (Prasad et al., 1998). In this study, selected strains and commercial strains exposed to $1.0 \%$ bile salt for $2 \mathrm{~h}$. As
Table 1. Acid tolerance of strains isolated from Kimchi and commercial strains when incubated at $\mathrm{pH}$ for $2 \mathrm{~h}$

\begin{tabular}{|c|c|c|c|}
\hline \multirow{2}{*}{ Name } & \multicolumn{3}{|c|}{ Viable cell counts (Log CFU/mL) } \\
\hline & Control & $1 \mathrm{~h}$ & $2 \mathrm{~h}$ \\
\hline DKL109 & $8.04 \pm 0.10$ & $5.96 \pm 0.24$ & $5.98 \pm 0.15$ \\
\hline DKL119²) & $8.77 \pm 0.12$ & $8.46 \pm 0.15$ & $8.26 \pm 0.24$ \\
\hline DKL121 $1^{3)}$ & $8.13 \pm 0.16$ & $7.99 \pm 0.09$ & N.D \\
\hline DKL128 $8^{4)}$ & $8.26 \pm 0.24$ & $6.00 \pm 0.04$ & N.D \\
\hline $\mathrm{LC}-10^{5)}$ & $8.26 \pm 0.24$ & N.D ${ }^{7}$ & N.D \\
\hline LP-5 $5^{6)}$ & $7.99 \pm 0.01$ & N.D & N.D \\
\hline
\end{tabular}

${ }^{1)}$ DKL109 (L. plantarum)

${ }^{2)}$ DKL119 (L. plantarum)

${ }^{3)}$ DKL121 (L. paracasei)

${ }^{4)}$ DKL128 (L. casei)

${ }^{5)}$ L. casei (LC-10, Culture system, USA)

${ }^{6)}$ L. plantarum (LP-5, Culture system, USA)

${ }^{7)}$ N.D, Not detected $<10^{6}$

All values are mean $\pm \mathrm{SD}$ of triplicates.

shown in Table 2, the stains isolated from Kimchi evidenced a good survival in the presence of $1.0 \%$ bile salt, even though the viable cell counts of DKL109 and $L$. casei DKL128 decreased approximately 2 log cycles.

It was revealed that DKL119 had the highest tolerance against bile salt and acid in this study. Similar studies (Lee et al., 2011; Lee et al., 2012; Lim and Im, 2009) were conducted on L. plantarum strain isolated from Kimchi and makgeolli, traditional Korean rice wine. They also indicated that L. plantarum strains had the acid and bile tolerance comparing with other species. DKL128 showed the least tolerance to acid and bile as comparing with other isolated strains. Other studies (Lim and Im, 2009; Mishra and Prasad, 2005) also showed that the growth of $L$. casei was inhibited in the presence of oxgall.

Table 2. Bile tolerance of strains isolated from Kimchi and commercial strains at $1.0 \%$ oxgall for $2 \mathrm{~h}$

\begin{tabular}{lccc}
\hline \hline \multirow{2}{*}{ Name } & \multicolumn{3}{c}{ Viable cell counts (Log CFU/mL) } \\
\cline { 2 - 4 } & Control & $1 \mathrm{~h}$ & $2 \mathrm{~h}$ \\
\hline DKL109 $^{1)}$ & $8.04 \pm 0.10$ & $6.00 \pm 0.09$ & $6.00 \pm 0.04$ \\
DKL119 $^{2)}$ & $8.77 \pm 0.12$ & $8.26 \pm 0.24$ & $8.59 \pm 0.11$ \\
DKL121 $^{3)}$ & $8.13 \pm 0.16$ & $7.90 \pm 0.05$ & $8.00 \pm 0.04$ \\
DKL128 $^{4)}$ & $8.26 \pm 0.24$ & $6.59 \pm 0.11$ & $6.46 \pm 0.15$ \\
LC-10 $^{5)}$ & $8.26 \pm 0.24$ & $6.69 \pm 0.09$ & N.D \\
LP-5 $^{7)}$ & $7.99 \pm 0.01$ & $7.96 \pm 0.23$ & $8.26 \pm 0.24$ \\
\hline
\end{tabular}

${ }^{10}$ DKL109 (L. plantarum)

${ }^{2)}$ DKL119 (L. plantarum)

${ }^{3)}$ DKL121 (L. paracasei)

${ }^{4)}$ DKL128 (L. casei)

${ }^{5)}$ L. casei (LC-10, Culture system, USA)

${ }^{6)}$ L. plantarum (LP-5, Culture system, USA)

${ }^{77}$ N.D, Not detected $<10^{6}$

All values are mean $\pm \mathrm{SD}$ of triplicates. 


\section{Enzyme activities}

Yogurt production begins with the breakdown of lactose into glucose and galactose, a process catalyzed by $\beta$ galactosidase. As a result of its hydrolytic activity, $\beta$-galactosidase is mainly used in the food industry to reduce the lactose concentration in milk (Rhimi et al., 2009). As shown in Fig. 1, DKL121 showed the highest $\beta$-galactosidase activity within selected strains but its activity was lower than commercial strain, ST-body1. Liang et al. (2011) reported that a $\beta$-galactosidase producing bacterium isolated from Kimchi and was identified as L. platarum group. To evaluate the activity in $\beta$-galactosidase of selected strains, changes in sugar contents of fermented milk were determined (Table 3). Lactose content (around 5\%) in milk reduced to $3.20-4.25 \%$ in fermented

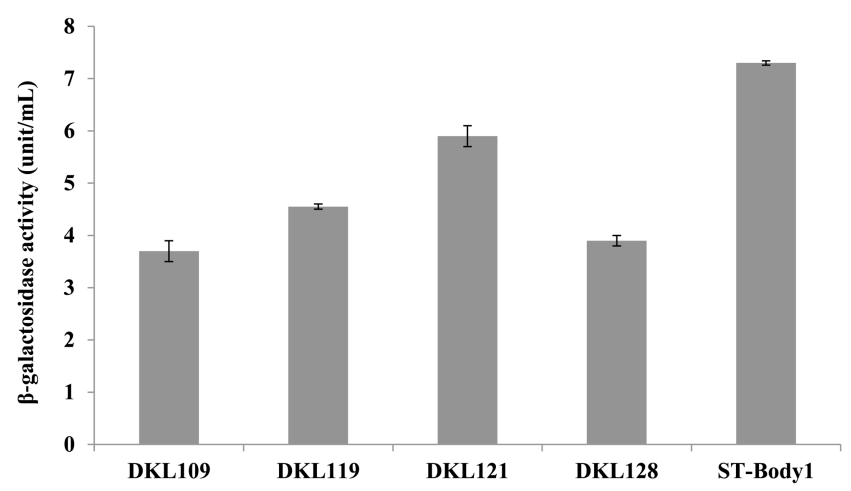

Fig. 1. Comparison of $\beta$-galactosidase activity of strains isolated from Kimchi and commercial strain. DKL109, $L$. plantarum; DKL119, L. plantarum; DKL121, L. paracasei; DKL128, L. casei; and S. thermophilus ST-Body1. milk produced by isolated strains. As a result of hydrolytic activity by $\beta$-galactosidase, $1.66-2.10 \%$ of galactose was detected, but glucose was not detected. This result was consistent with Richmond et al. (1987) reporting that lactose content and galactose content were 3.70, and $1.04 \%$, respectively, and glucose remained at trace levels.

In the preparation of various fermented milk products, the proteolytic activity of starter culture is also important because it leads to liberation of peptides and amino acids. Many amino acids produced are essential for the growth of several cultures and have considerable effects on the physical structure, taste and flavor of dairy products (Gandhi, 2007; Heller, 2001). It was found that all isolated strains produced clearing zones when tested for proteolytic activity on milk agar. The clearing zone diameter

Table 3. HPLC analysis of contents of lactose, galactose and glucose in raw milk and fermented milk with strains isolated from Kimchi

\begin{tabular}{|c|c|c|c|}
\hline \multirow{2}{*}{ Name } & \multicolumn{3}{|c|}{ Contents (\%) } \\
\hline & Lactose & Galactose & Glucose \\
\hline Raw milk & $4.99 \pm 0.07$ & N.D ${ }^{5)}$ & N.D \\
\hline DKL109') & $3.20 \pm 0.09$ & $1.66 \pm 0.05$ & N.D \\
\hline DKL119²) & $4.25 \pm 0.19$ & $1.99 \pm 0.10$ & N.D \\
\hline DKL121 $1^{3)}$ & $3.37 \pm 0.25$ & $1.67 \pm 0.16$ & N.D \\
\hline DKL1284) & $3.78 \pm 0.05$ & $2.10 \pm 0.11$ & N.D \\
\hline
\end{tabular}

${ }^{1)}$ DKL109 (L. plantarum)

${ }^{2)}$ DKL119 (L. plantarum)

${ }^{3)}$ DKL121 (L. paracasei)

${ }^{4)}$ DKL128 (L. casei)

${ }^{5)}$ N.D, Not detected

All values are mean $\pm \mathrm{SD}$ of triplicates.

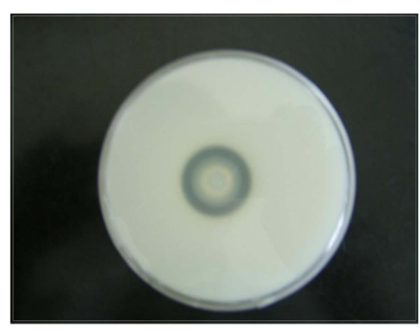

DKL109

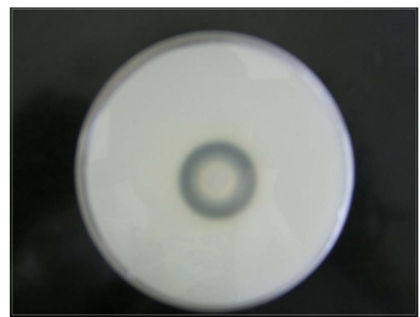

DKL121

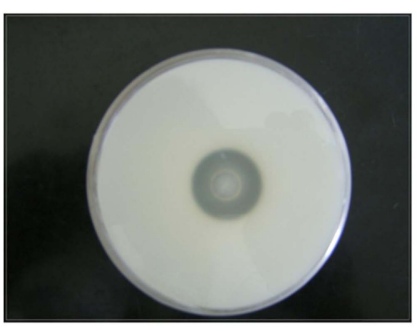

DKL119

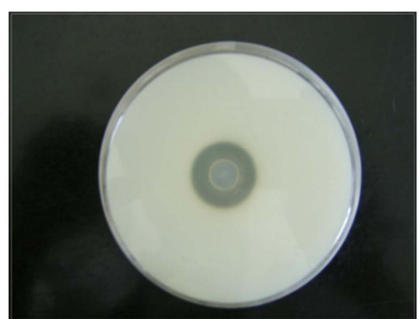

DKL128

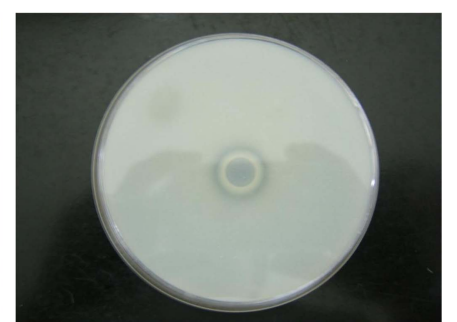

ST-Body1

Fig. 2. Comparison of proteolytic activity strains isolated from Kimchi and commercial strain in skim milk agar plate. DKL109, L. plantarum; DKL119, L. plantarum; DKL121, L. paracasei; DKL128, L. casei; and S. thermophilus ST-Body1. 
was larger than that produced by ST-body1.

\section{Response to freeze-thaw challenge}

Understanding the cold-shock induced cryotolerance of probiotics is important for basic research and also for applied studies such as development of commercial starter cultures. The isolated strains were submitted to a freeze-thaw challenge, consisting of 3 cycles of freezing $\left(-40^{\circ} \mathrm{C}, 24 \mathrm{~h}\right)$ and thawing $\left(37^{\circ} \mathrm{C}, 3 \mathrm{~min}\right)$. As shown in Fig. 3, the cultures showed different stability after being frozen at $-40^{\circ} \mathrm{C}$ for $24 \mathrm{~h}$. DKL121 and DKL128 strain showed high resistance to freeze-thaw challenge. The viability of DKL119 slightly decreased after the first freezing-thawing cycle, but that was gradually recovered. DKL109 showed the lowest resistance to freeze-thaw challenge. It seemed that L. platarum species. It can be noted that the process of freezing appeared to have different effects on different LAB as well as different effects on strains within the same genus (Kim and Dunn, 1997). The cold-shock induced cyrotolerance in other LAB also have been reported (Kim and Dunn, 1997; Rivals et al., 2007). In their studies, the survivability of LAB was much lower than that of the

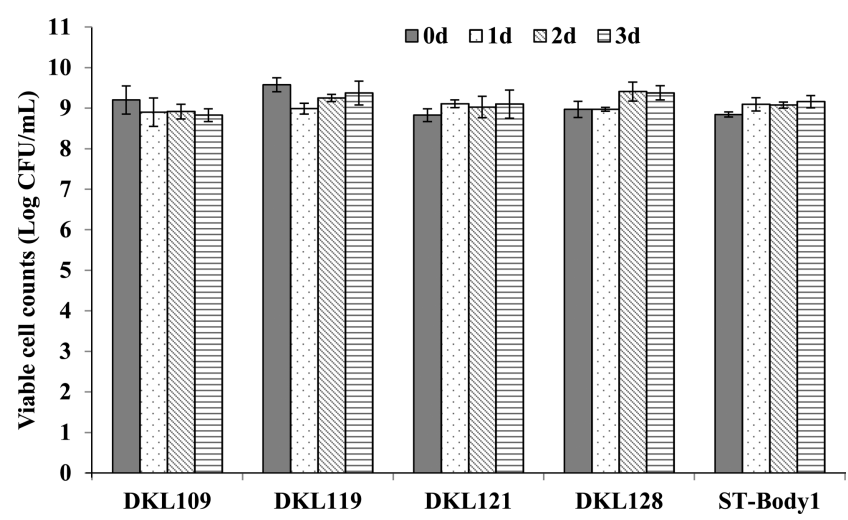

Fig. 3. Changes in viable cell counts of strains isolated from Kimchi and commercial strain in MRS broth after three freezing-thawing cycles. DKL109, L. plantarum; DKL119, L. plantarum; DKL121, L. paracasei; DKL128, L. casei; and S. thermophilus ST-Body1. strains selected in this study.

\section{Yogurt preparation with selected cultures}

Another purpose of this study was an application of strains isolated from Kimchi to fermented dairy products as a starter culture. Lactic cultures occupy the key positions in the preparation of fermented dairy products, as the success or failure of such product is directly related to the types of starter used. An ideal starter culture should be quick and steady in acid production, produce product with fine and clean lactic flavor and not produce any pigments, gas, off-flavor and bitterness in the finished products (Ghandi, 2007).

DKL119 and DKL121 not only met with these criteria but showed compatibly better tolerance in sub-lethal conditions and enzymatic activities than DKL109 and DKL128. Moreover, later two strains produced noticeable Kimchi flavor during fermentation of milk in preliminary study. Therefore DKL119 and DKL121 were selected as starter culture for the yogurt preparation. The viable cell counts and titratable acidity of yogurt fermented with these strains were compared with those of yogurt fermented with ST-body1, a well-known commercial starter culture.

As shown in Table 4, DKL119 developed acidity much faster than commercial strain, that is, it reached the target acidity (0.65-0.70) after $6.5 \mathrm{~h}$ but DKL121 and ST-body 1 did after $8 \mathrm{~h}$. At the target acidity the viable cell count of all strains tested reached around $9 \mathrm{Log} \mathrm{CFU} / \mathrm{mL}$.

The changes in acidity and viable cell count during storage at $10^{\circ} \mathrm{C}$ are shown in Table 6 and Table 7, respectively. During storage, the counts of DKL119 and DKL121 remained stable over the 15 days of storage. Acidity development in yogurt prepared by isolated strains was slightly higher than ST-body1 but there was no significant difference. With these results, it was found an applicability of strains isolated from Kimchi into the milk fermentation as a starter culture.

Table 4. Changes in titratable acidity of yogurt fermented by strains isolated from Kimchi and commercial strain during fermentation

\begin{tabular}{lccccc}
\hline \hline & \multicolumn{5}{c}{ Titrable acidity (\%) } \\
\cline { 2 - 6 } & $0 \mathrm{~h}$ & $2 \mathrm{~h}$ & $4 \mathrm{~h}$ & $6 \mathrm{~h}$ & $8 \mathrm{~h}$ \\
\hline DKL119 & $0.20 \pm 0.01$ & $0.27 \pm 0.01$ & $0.39 \pm 0.01$ & $0.60 \pm 0.02$ & $0.85 \pm 0.06$ \\
DKL121 $^{2)}$ & $0.21 \pm 0.02$ & $0.26 \pm 0.01$ & $0.35 \pm 0.00$ & $0.51 \pm 0.01$ & $0.68 \pm 0.01$ \\
ST-Body 1 $^{3)}$ & $0.17 \pm 0.02$ & $0.31 \pm 0.01$ & $0.39 \pm 0.01$ & $0.50 \pm 0.01$ & $0.67 \pm 0.00$ \\
\hline
\end{tabular}

${ }^{1)}$ DKL119 (L. plantarum)

${ }^{2)}$ DKL121 (L. paracasei)

${ }^{3)}$ S. thermophilus ST-Body1

All values are mean $\pm \mathrm{SD}$ of three replicates. 
Table 5. Changes in viable cell counts of yogurt fermented by strains isolated from Kimchi and commercial strain during fermentation

\begin{tabular}{lccccc}
\hline \hline & \multicolumn{5}{c}{ Viable cell counts (Log CFU/mL) } \\
\cline { 2 - 6 } & $0 \mathrm{~h}$ & $2 \mathrm{~h}$ & $4 \mathrm{~h}$ & $6 \mathrm{~h}$ & $8 \mathrm{~h}$ \\
\hline DKL119 $^{1)}$ & $7.26 \pm 0.24$ & $7.59 \pm 0.11$ & $8.30 \pm 0.02$ & $9.46 \pm 0.15$ & $9.30 \pm 0.08$ \\
DKL121 $^{2)}$ & $6.96 \pm 0.24$ & $6.99 \pm 0.13$ & $8.26 \pm 0.24$ & $8.54 \pm 0.28$ & $9.04 \pm 0.01$ \\
ST-Body1 $^{3)}$ & $6.00 \pm 0.04$ & $6.98 \pm 0.18$ & $8.26 \pm 0.24$ & $8.54 \pm 0.28$ & $9.04 \pm 0.07$ \\
\hline
\end{tabular}

${ }^{10} \operatorname{DKL} 119$ (L. plantarum)

${ }^{2)}$ DKL121 (L. paracasei)

${ }^{3)}$ S. thermophilus ST-Body1

All values are mean $\pm \mathrm{SD}$ of three replicates.

Table 6. Changes in titratable acidity of yogurt fermented by strains isolated from Kimchi and commercial strain during storage period

\begin{tabular}{|c|c|c|c|c|}
\hline & \multicolumn{4}{|c|}{ Titrable acidity (\%) } \\
\hline & $0 \mathrm{~d}$ & $5 \mathrm{~d}$ & $10 \mathrm{~d}$ & $15 \mathrm{~d}$ \\
\hline DKL119 ${ }^{1)}$ & $0.65 \pm 0.02$ & $0.78 \pm 0.02$ & $0.93 \pm 0.02$ & $1.12 \pm 0.03$ \\
\hline DKL121 & $0.68 \pm 0.01$ & $0.85 \pm 0.02$ & $1.00 \pm 0.04$ & $1.11 \pm 0.02$ \\
\hline ST-Body ${ }^{3)}$ & $0.67 \pm 0.02$ & $0.72 \pm 0.01$ & $0.83 \pm 0.02$ & $0.91 \pm 0.01$ \\
\hline \multicolumn{5}{|c|}{$\begin{array}{l}{ }^{15} \text { DKL119 (L. plantarum) } \\
{ }^{2)} \text { DKL121 (L. paracasei) } \\
\text { All values are mean } \pm \text { SD of three replicates. } \\
\text { Table 7. Changes in viable cell counts of yogurt fermented by } \\
\text { strains isolated from Kimchi and commercial strain } \\
\text { during storage period }\end{array}$} \\
\hline & \multicolumn{4}{|c|}{ Viable cell counts ( $\log \mathrm{CFU} / \mathrm{mL})$} \\
\hline & $0 \mathrm{~d}$ & $5 \mathrm{~d}$ & $10 \mathrm{~d}$ & $15 \mathrm{~d}$ \\
\hline DKL119 & $9.30 \pm 0.06$ & $9.54 \pm 0.28$ & $9.26 \pm 0.24$ & $9.27 \pm 0.19$ \\
\hline DKL1212) & $9.01 \pm 0.20$ & $9.26 \pm 0.24$ & $9.29 \pm 0.13$ & $9.26 \pm 0.24$ \\
\hline ST-Body $1^{3)}$ & $9.04 \pm 0.07$ & $9.46 \pm 0.15$ & $9.37 \pm 0.09$ & $9.30 \pm 0.02$ \\
\hline
\end{tabular}

${ }^{10}$ DKL119 (L. plantarum)

${ }^{2)}$ DKL121 (L. paracasei)

${ }^{3)} S$. thermophilus ST-Body1

All values are mean $\pm \mathrm{SD}$ of three replicates.

\section{Conclusion}

This study was undertaken to isolate and identify strains from Kimchi for incorporation in dairy products. L. plantarum DKL109, L. plantarum DKL119, L. paracasei DKL121 and L. casei DKL128 were selected out of 106 strains isolated from Kimchi samples. L. plantarum DKL119 was found to be the most promising strain as probiotics and starter culture because it showed relatively good results in tolerance to acid and bile salt, cold-shock induced cryotolerance, and $\beta$-galactosidase and proteolytic activity. Moreover, it was revealed that strains isolated from Kimchi can be applicable for the milk fermentation as a starter culture. L. plantarum DKL119 showed promising results in the yogurt preparation as it was quick in acid production during fermentation and showed stable viability during storage. Further study on the development of fermented dairy product by $L$. plantarum DKL119 in combination with other lactic acid bacteria will be conducted.

\section{References}

1. Bamidele, T. A., B. A. Adeniyi, S. T. Ogunbanwo, S. I. Smith, and Omonigbehin. E. A. (2011) Antibacterial Activities of Lactic Acid Bacteria Isolated from Selected Vegetables Grown in Nigeria: A Preliminary Report. Sierra Leone J. Biomedical Res. 3, 128-132.

2. Gandhi, D. N. (2007) Microbiology of Fermented Dairy Products. Food and Industrial Microbiology. National Science Digital Library at NISCAIR, India, pp. 1-31

3. Gerez, C. L., Font de Valdez, G., Gigante, M. L., and Grosso, C. R. F. (2012) Whey protein coating bead improves the survival of the probiotic Lactobacillus rhamonosus CRL 1505 to low pH. Lett. Appl. Microbiol. 54, 552-556.

4. Heller, K. J. (2001) Probiotic bacteria in fermented foods: product characteristics and starter organisms. Am. J. Clin. Nutr. 73, 374S-379S.

5. Jalili, H., Razavi, S. H., Safari, M., and Malcata, F. X. (2009) Enhancement of growth rate and $\beta$-galactosidase activity, and variation in organic acid profile of Bifidobacterium animalis subsp. lactis Bb12. Enzyme Microbial Technol. 45, 469-476.

6. Kim, B., Lee, J., Jang, J., Kim, J., and Han, H. (2003) Leuconostoc inhae sp. nov., a alctic acid bacterium isolated from kimchi. Int. J. Syst. Evol. Microbiol. 53, 1123-1126.

7. Kim, C. H. and Kwak, H. S. (1993) Comparison of HPLC method with Bertrand and Lane-Eynon methods for the quantitative analysis of lactose in milk. Korean J. Dairy Sci. 15, 203-208.

8. Kim, W. S. and Dunn, N. W. (1997) Identification of a cold shock gene in lactic acid bacteria and the effect of cold shock on cryotolerance. Curr. Microbiol. 35, 59-63.

9. Lee, H., Yoon, H., Ji, Y., Kim, H., Park, H., Lee, J., Shin, H., and Holzapfel, W. (2011) Functional properties of Lactoba- 
cillus strains isolated from kimchi. Int. J. Food Microbiol. 145, 155-161.

10. Lee, K. H. Park, J. Y., Jeong, S. J., Kwon, G. H., Lee, H. J., Chang, H. C., Chung, D. K., Lee, J. H., and Kim, J. H. (2007) Characterization of paraplantaricin $\mathrm{C} 7$, a novel bacteriocin produced by Lactobacillus paraplantarum $\mathrm{C} 7$ isolated from Kimchi. J. Microbiol. Biotechnol. 17, 287-296.

11. Lee, S. G., Lee, K. W., Park, T. H., Park, J. Y., Han, N. S., and Kim, J. H. (2012) Proteomic analysis of proteins increased or reduced by ethanol of Lactobacillus plantarum ST4 isolated from Makgeolli, traditional Korean rice wine. J. Microbiol. Biotechnol. 22, 516-525.

12. Liang, Z. Q., Srinivasan, S., Kim, Y. J., Kim, H. B., Wang, H. T., and Yang, D. C. (2011) Lactobacillus kimchicus sp. nov., a $\beta$-galactosidases producing bacterium isolated from kimchi. Int. J. Syst. Evol. Microbiol. 61, 894-897.

13. Lim, S. M. and Im, D. S. (2009) Screening and characterization of probiotic lactic acid bacteria isolated from Korean fermented foods. J. Microbiol. Biotechnol. 19, 178-186.

14. Mishra, V. and Prasad, D. N. (2005) Application of in vitro methods for selection of Lactobacillus casei strains as potential probiotics. Int. J. Food Microbiol. 103, 109-115.

15. Prasad, J., Gill, H., Smart, J., and Gopal, P. K. (1998) Selection and characterization of Lactobacillus and Bifidobacterium strains for use as probiotic. Int. Dairy J. 8, 993-1002.

16. Richmond, M. L., Harte, B. R., Gray, J. I., and Stine, C. M. (1987) Determination of sugars in yogurt and microbiological media by high performance liquid chromatography during processing and subsequent storage. J. Dairy Sci. 70,
1140-1147

17. Rhimi, M. R., Aghajari, N., Jaouadi, B., Juy, M., Boudebbouze, S., Maguin, E., Haser, R., and Bejar, S. (2009) Exploring the acidotolerance of $\beta$-galactosidase from Lactobacillus delbrueckii subsp. bulgaricus: an attractive enzyme for lactose bioconversion. Res. Microbiol. 160, 775-784.

18. Riffel, A., and Brandelli, A. (2006) Keratinolytic bacteria isolated from feather waste. Brazilian J. Microbiol. 37, 395399.

19. Rivals, J. P., Beal, C., Thammavongs, B., Gueguen, M., and Panoff, J. M. (2007) Cryotolerance of Lactobacillus delbrueckii subsp. bulgaricus CFL1 is modified by acquisition of antibiotic resistance. Cryobiology 55, 19-26.

20. Rivera-Espinoza, Y. and Gallardo-Navarro, Y. (2010) Nondairy probiotic products. Food Microbiol. 27, 1-11.

21. Shin, M. S., Han, S. K., Ryu, J. S., Kim, K. S., and Lee, W. K. (2008) Isolation and partial characterization of a bacteriocin produced by Pediococcus pentosaceus K23-2 isolated from Kimchi. J. Appl. Microbiol. 105, 331-339.

22. Succi, M., Tremonte, P., Reale, A., Sorrentino, E., Grazia, L., Pacifico, S., and Coppola, R. (2005) Bile salt and acid tolerance of Lactobacillus rhamnosus strains isolated from Parmigiano Reggiano cheese. FEMS Microbiol. Lett. 244, 129137.

23. Yang, E. J. and Chang, H. C. (2009) Analysis of pYC2, a cryptic plasmid in Lactobacillus sakei BM5 isolated from kimchi. Biotechnol. Lett. 31, 123-130.

(Received 2012.12.20/Revised 2013.1.16/Accepted 2013.2.7) 